\title{
An Identification Procedure for Woolly Soft-flesh Peaches by Instrumental Assessment
}

\author{
C. Ortiz ${ }^{1}$; P. Barreiro ${ }^{1}$; M. Ruiz-Altisent ${ }^{1} ;$ F. Riquelme ${ }^{2}$

\begin{abstract}
${ }^{1}$ Physical Properties Laboratory. Rural Engineering Department, Politechnic University of Madrid; c/Ciudad Universitaria s/n. Edificio de Motores y Máquinas, Departamento de Ingenieria Rural, E.T.S.I.A. 28040 Madrid, Spain; e-mail of corresponding author: labptopfis3@iru.etsia.upm.es
\end{abstract} \\ 2Institute of Soil Science and Applied Biology CSIC; CEBAS-CSIC, P.O. Box 4195, 30080 Murcia, Spain; e-mail: friquelm@natura.cebas.csic.es
}

\begin{abstract}
Woolliness in peaches, a negative attribute of sensory texture characterized by the lack of crispness and juiciness, also known as mealiness in other fruits, has been identified fruit-by fruit by instrumental means. The use of a non-supervised clustering data analysis procedure, studying crispness and juiciness, enables four instrumental degrees of texture degradation to be defined, of which woolliness appears to be the last stage. This procedure also provides some knowledge on several experimental factors (ripeness stages, storage time and storage temperature) with regard to the onset of woolliness. It is confirmed through this study that, in cv. Maycrest peaches, woolliness starts to appear alter 2 weeks of storage at $5^{\circ} \mathrm{C}$.

Fruits classified at harvest in 'first' and 'second' ripeness stages are more susceptible to woolliness than those in the third ripeness stage. This clustering procedure may also be effective for the study of other species, varieties and quality attributes of fruits.
\end{abstract}

\section{Introduction}

Woolliness or leatheriness in peaches (mealiness in other fruits) is a negative attribute of sensory texture, characterized by the lack of juiciness without variation of the tissue water content. Besides the lack of juiciness and flavour, in peaches it is associated with internal browning near the stone and incapacity of ripening although there is external ripe appearance. It is considered as a physiological disorder that appears in stone fruits when an unbalanced pectolitic enzyme activity during storage occurs (Harker \& Hallett, 1992).

At a cellular level, the lack of juiciness in peaches with woolly textures is caused by gel structures that retain the water molecules. These gel structures have high molecular weight and many ramifications which cause the woolly sensation in the mouth (Kailasapathy \& Melton. 1992).

Consumers and retailers in California considered woolly peaches a problem that should be specifically addressed (Bruhn, 1995). Also a survey of Madrid retailers showed how mealiness in fruits is considered a negative attribute, which reduces sales and price (Lopez et. al., 1996).
When comparing mechanical and sensory appreciation of mealiness in apples, lack of crispness, of hardness and of juiciness were the major descriptors of the mealiness sensation (Barreiro et al., 1998a). Also in apples, a repertory grid carried out with consumers from different countries (Holland, United Kingdom, Spain, Belgium and France) showed that in all those five countries mealiness was considered opposite to crispness, hardness and juiciness (Izquierdo \& Costell, 1997). Later, it was shown that in peaches, woolliness is a lack of crispness, of hardness and of juiciness as well (Izquierdo \& Costell. 1998). Paoletti et al. in 1993 compared instrumental and sensory assessment of quality on selected commercial apple samples. This study showed that Magness-Taylor firmness (measured as maximum penetration force) had a 0.91 correlation coefficient with the sensory durezza (hardness); failure stress during compression showed a 0.92 correlation coefficient with the sensory fratturabilita (crispness); instrumental juiciness showed a 0.74 correlation coefficient with the sensory assessment of succosita (juiciness). These conclusions have been used in the present research.

The data analysis procedures used until now for mealiness and woolliness assessment have been mainly basic 
statistics, principal component analysis, ANOVA. MANOVA, preference maps, or linear regressions. With the objective of improving classification tools, new procedures like clustering have shown good possibilities for fruit-by-fruit identification (Barreiro et al., 1998b).

The objectives of this research were: to develop a fruit by fruit data analysis technique that enables the identification of individual woolly peach fruits on the basis of instrumental measurements; and to study the effect of ripeness stage, storage temperature and storage time, on the onset of woolliness.

\section{Materials and methods}

The peach variety Moycrest, used for this study was grown in Murcia during the 1996 season and was treated under a factorial experimental design. Three factors were studied.

(1) Ripeness stage. Three different stages of ripeness at harvest were selected, by experts, in fruits harvested on the same date in the same orchard, and according mainly to visual colour. The average reflectance values of the fruits, at a wavelength of $680 \mathrm{~nm}$ (chlorophyll-absorbing band) were: first or early ripeness stage (reflectance of $34.6 \% \pm 6.83$ ); second or medium ripeness stage (reflectance of $41.4 \% \pm 6.88$ ); and third or late ripeness stage (reflectance of $43.5 \%$ \pm 6.78 ).

(2) Storage temperature. Two different storage temperatures were tested, in air: +1 and $+5^{\circ} \mathrm{C}$. This last temperature was selected to assure the presence of woolly fruits (this temperature is reached usually in commercial conditions).

(3) Storage period. Five different modalities were tested for this factor: at harvest, and weekly for a period of 1 month. The fruits were stored in the Institute of Soil Science and Applied Biology (CEBAS) in Murcia and sent to the Physical Properties Laboratory (LPF) the night before the measurements were carried out in both testing sites. Isolated boxes with ice bags were used for transportation.

The total amount of fruits used for the experimental design (sample size of 10 fruits) was: 270 peaches at three ripeness stages, two storage temperatures, and from four durations of storage.

The tests carried out on these samples can be summarized as follows:

(1) weighing of samples individually;

(2) optical tests for the visible spectrum and colour assessment, using a Minolta spectrophotometer CM-50I, with samples characterized by percentage of reflectance, at a bandwidth of $10 \mathrm{~nm}$, centred on $680 \mathrm{~nm}$ (R680);

(3) chemical tests to determine soluble solid content, measured by a digital refractometer PR-101 ATAGO, and titratable or total acidity using $\mathrm{NaOH}$ $0.1 \mathrm{~N}$ and phenolphthalein indicator for calculating $\mathrm{meq} / l$, and

(4) mechanical tests: at the initial stage, for the instrumental assessment of quality texture. Four mechanical tests were selected.

(a) Magness-Taylor penetration test. Using a Texture Analyser XT2 on whole fruits (without skin) with a $8 \mathrm{~mm}$ diameter rod, maximum penetration of $8 \mathrm{~mm}$ was applied at a rate of $20 \mathrm{~mm} / \mathrm{min}$. The maximum penetration force was registered and is referred to as the Magness-Taylor firmness (MT) measured in N.

(b) Confined compression test. This was carried out with the same texture machine on cylindrical samples of $1.4 \mathrm{~cm}$ in height and $1.4 \mathrm{~cm}$ in diameter. Samples were confined in a disc with a height of $1.4 \mathrm{~cm}$ and a hole of the same diameter as the cylindrical sample (Fig. 1). A maximum deformation of $2.0 \mathrm{~mm}$ was applied at a rate of $20 \mathrm{~mm} / \mathrm{min}$. The rod used in this test had a $12.5 \mathrm{~mm}$ diameter in order to avoid rod/disc contacts during compression. Deformation was immediately removed at the same rate; one repetition was made per fruit. The following parameters were registered through these tests: maximum force in $\mathrm{N}$, at $2 \mathrm{~mm}$ deformation; force/deformation ratio within the range of elastic behaviour in $\mathrm{N} / \mathrm{mm}$ (this magnitude being referred to as compression hardness); degree of permanent deformation (PD), calculated as a percentage of permanent deformation over the total deformation of $2 \mathrm{~mm}$, this magnitude being used as a lack of elasticity, i.e. degree of non-recoverable deformation; juice area (JA) in $\mathrm{mm}^{2}$ of the spot accumulated on a filter paper placed underneath the sample during the test, and this magnitude being used as compression juiciness (Paoletti. 1993); absorbed energy during compression (CE) in $\mathrm{N}$ mm by integration of the area below the force deformation curve until $2 \mathrm{~mm}$ of deformation is achieved; and restitution energy after compression (RE) in $\mathrm{N} \mathrm{mm}$, by integration of the area below force deformation curve during unloading (when deformation was removed from $2 \mathrm{~mm}$ to the permanent deformation).

(c) Compression rupture test. This was carried out with the same texture machine on fruit samples of size similar to those for the previous test; one repetition was made per lruit. In this case a flat plate was used (diameter $3.2 \mathrm{~cm})$. A non-confined sample $(1.4 \mathrm{~cm}$ in diameter and $1.4 \mathrm{~cm}$ in height) was compressed at a $20 \mathrm{~mm} / \mathrm{min}$ speed rate until the rupture point was achieved, registering the maximum force at that point. This parameter is referred to as the compression crispness in $\mathrm{N}$. 

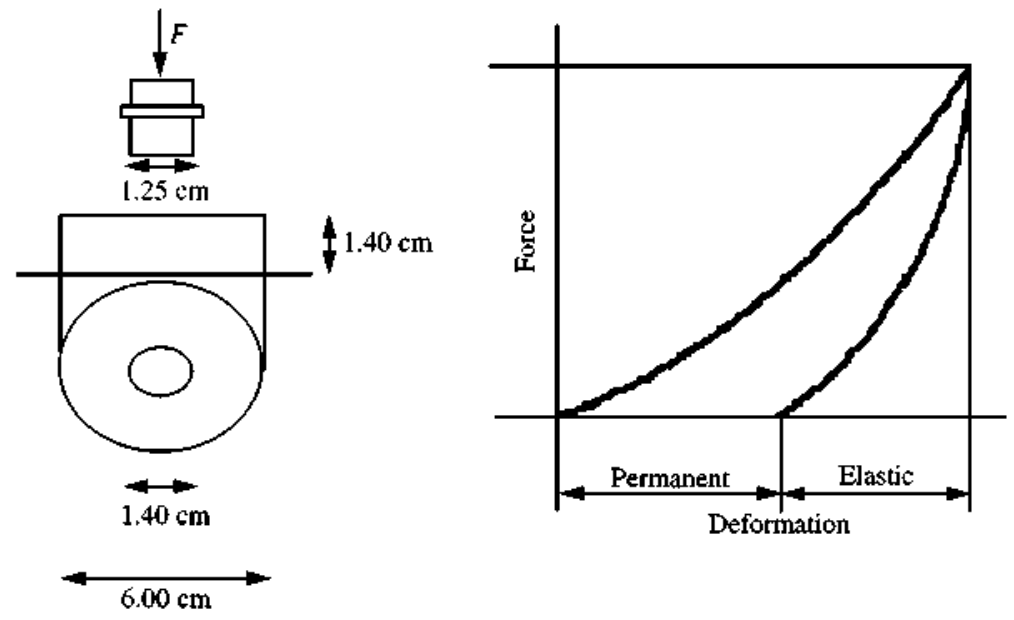

Fig. 1. Confined compression test (force $F$ required to produce a maximum deformation of 2 mu of which part is permanent deformation with some elastic recovery)

(d) Shear rupture test. For this test a special device was developed in 1992 by Jaren and Ruiz-Altisent, comprising an $8 \mathrm{~cm}$ metacrilate cube, with a rectangular slot ( $3 \mathrm{~cm}$ long by $0.7 \mathrm{~cm}$ wide) through the centre. A sliding cutter, $3 \mathrm{~cm}$ wide by $9 \mathrm{~cm}$ long by $0.7 \mathrm{~cm}$ thick was inserted though this slot. Both the sliding cutter and the cube have a transversal cylindrical hole which are held in alignment at rest by spring tensioning the sliding cutter. A fruit sample was placed in the cylindrical hole and the rectangular cutter depressed to shear the sample. Two cylindrical nylon pieces joined together by a rubber band compress the sample to maintain it in a fixed position during the test (Fig. 2).

This test was carried out on fruit samples of $1.4 \mathrm{~cm}$ in diameter and $2.0 \mathrm{~cm}$ in length. In this test, an increasing deformation was applied at a rate of $20 \mathrm{~mm} / \mathrm{min}$ until the sample was sheared; one repetition was carried out per fruit. The maximum shear force was registered, and is referred to as shear crispness (SF) in N (Paoletti. 1993).

All data obtained within these tests were analysed by Statistica 4.5. for Windows: subprograms devoted to basic statistics, ANOVA, non-linear regression and clustering.

Sigmoidal modelling was applied to some parameters. The sigmoidal equation applied is

$$
y=-A\left(1+\mathrm{e}^{-r(t-i)}\right)+y_{0}
$$

where $A$ is the range of variation of the parameter modelled, $r$ is the rate of change, $i$ is the inflection point, $y$ is the parameter modelled, $y_{0}$ is the maximum value of the parameter modelled, and $t$ is the time of storage in weeks.

\section{Results and discussion}

The histograms of the instrumental variables were first studied in order to know distribution characteristics. Although the histograms for most of the variables, for 270 fruits, showed unimodal distributions, some of them as the shear crispness (SF, Fig. 3) showed bimodal ones. This bimodal distribution is in accordance with a sigmoidal behaviour (Table 1) and indicates the presence of two different groups of fruits, i.e. 'crispy' and 'non-crispy' and a rapid change from one to the other. On the variables: $M T, F D, R F$ and $S F$ that showed bimodal distributions, a non-supervised clustering analysis was carried out, classifying the peaches into two groups ('crispy" and 'non-crispy'); centred and reduced data were used to avoid the effect of differences in the magnitude of the variables on the clustering procedure.

Once fruits were classified into crispy (average $R F$ of $83.80 \mathrm{~N}$ and average $S F$ of $64.53 \mathrm{~N}$, and non-crispy fruits (average $R F$ of $13.84 \mathrm{~N}$ and average $S F$ of $15.46 \mathrm{~N}$ ), an analysis of variance on the remaining fruit characteristics was carried out for each group separately. Besides the parameters used for the definition of crispy and noncrispy clusters, the highest significant differences between crispy and non-crispy fruits were found in: $P D, C E$ and $R E$ (highest $F$ values, Table 2, first column). Important differences between crispy and non-crispy fruits are also shown for acidity and for reflectance at $680 \mathrm{~nm}$. From these data, it is shown that crispy fruits correspond to high average values in $P D(39.06 \%)$, acidity $(156.57 \mathrm{meq} / l) . J A\left(379.53 \mathrm{~mm}^{2}\right)$ and sugar content $\left(10.84^{\circ}\right.$ Brix) when compared to non-crispy fruits which show lower than average values in these same parameters (Table 2). 


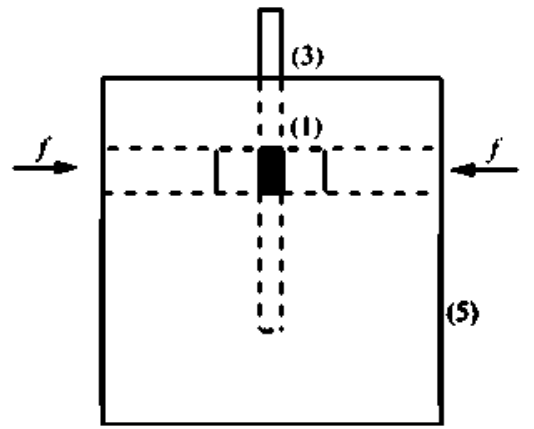

(a)

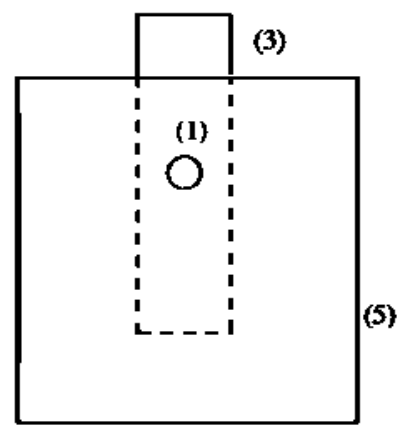

(a)

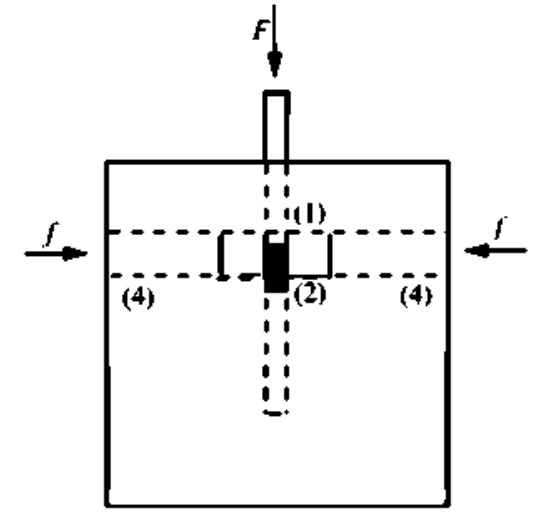

(b)

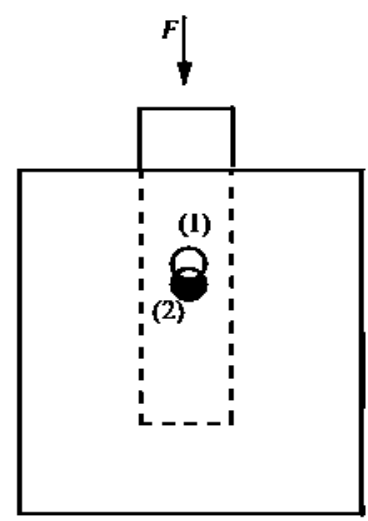

(b)

Fig. 2. Shear nupture test: front view (above) and lateral view (below): (a) a cylindrical frut sample is placed in the hole ff through the device and $(b)$ the fruit sample is sheared by the sliding cutter ander load $F$ for cylindrical frut samples $1+4 \mathrm{~cm}$ in diameter (right): (1) cylindrical fruit sample; (2) sheared fruit sample piece ander load $F$; (3) sliding cutter; (4) cylindrical nylon pieces and (5) metacrilate cube

According to the definition of woolliness as an attribute of non-crispness combined with lack of juice, it was necessary to classify in different degrees of juiciness within the 'non-crispy cluster'. Juiciness has a more grad-

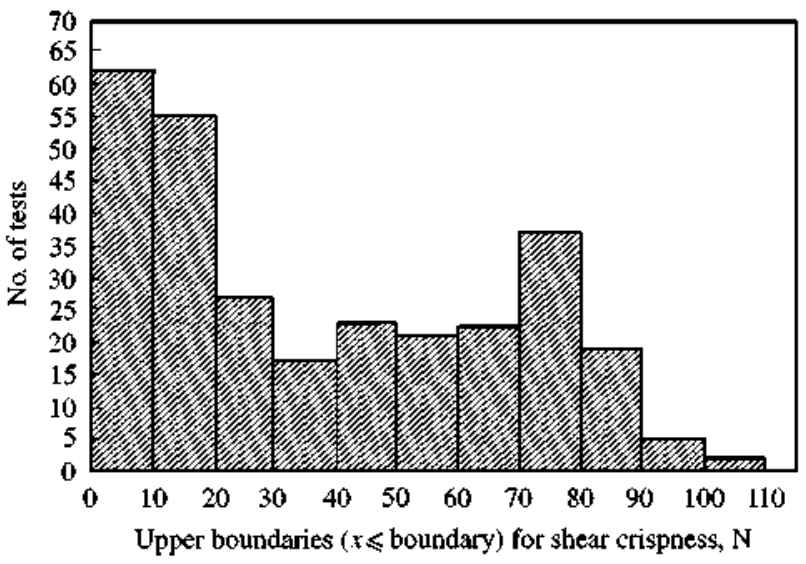

Fig. 3. Bimodal histogram observed for shear crispness, $N$ ual changing pattern than crispness and therefore no multi-modal distribution of juiciness data is observed through the histogram corresponding to the 270 fruits tested (Fig. 4). The appropriate procedure in this case was to carry out a partition of the juiciness data in several clusters within the criteria of obtaining a low intragroup variability (low standard deviation) combined with a good representation of the resulting groups in terms of number of members. The best partition of the non-crispy fruits (140 fruits) corresponds to three different juiciness categories (established according to the cluster analysis) which are labelled as high juiciness (H.J), intermediate juiciness (MJ) and low juiciness (LJ). The juiciness and crispness characteristics of the four fruit clusters: 'crispy'. 'non-crispy-high juiciness', 'non-crispy-intermediate juiciness' and 'non-crispy-low juiciness' are presented in Fig. 5. In this figure, it is shown that the juiciness average values for the non-crispy-high juiciness $\left(500 \mathrm{~mm}^{2}\right)$ and the non-crispy-intermediate juiciness $\left(350 \mathrm{~mm}^{2}\right)$ are comparable to the juiciness of the crispy fruits, while the 
Table 1

Estimated parameters for the adjusted sigmoidal curves corresponding to the first and the second ripeness stage fruits in cold storage at $5^{\circ}$; $R^{2}$, coefficient of determination

\begin{tabular}{|c|c|c|c|c|c|c|}
\hline Variable & Ripeness stage & $\begin{array}{l}\text { Maximum } \\
\text { walse }\left(y^{\theta}\right)\end{array}$ & $\begin{array}{l}\text { Range of } \\
\text { (ariation (A) }\end{array}$ & $\begin{array}{l}\text { Range of } \\
\text { change ( } r \text { ) }\end{array}$ & $\begin{array}{l}\text { Inflection } \\
\text { point (i) }\end{array}$ & $R^{2}$ \\
\hline \multirow[t]{2}{*}{ Reflectance at $680 \mathrm{~nm}$} & First & $47 \cdot 5$ & $42+38$ & -2.33 & 0.90 & 0.8840 \\
\hline & Second & 53 & $15 \cdot 52$ & $-2 \cdot 69$ & 1.89 & 0.5928 \\
\hline \multirow[t]{2}{*}{ Compression hardness } & First & 27 & $19 \cdot 15$ & $-8 \cdot 51$ & $1 \cdot 00$ & 0.6604 \\
\hline & Second & $17 \cdot 2$ & 13.88 & -3.01 & 1.48 & 0.6195 \\
\hline \multirow[t]{2}{*}{ Shear rupture crispness } & First & 75 & $57 \cdot 04$ & -3.37 & 0.90 & 0.8088 \\
\hline & Second & $34+2$ & $27 \cdot 22$ & $-5 \times 37$ & 1.30 & 0.5623 \\
\hline
\end{tabular}

group labelled as non-crispy-low juiciness shows consistently lower juiciness $\left(<200 \mathrm{~mm}^{2}\right)$. Therefore, this last cluster (Fig. 5), which corresponds to the end of the texture degradation process was labelled as 'woolly' fruits.

Once a non-supervised identification procedure of the woolly fruits was achieved, a study on the experimental factors (harvest date, fruit size, storage temperature and storage period) related to woolliness onset was carried out. The results of this study are shown in Table 3 which shows that the fruits labelled as 'woolly' appear mainly at a storage temperature of $5^{\circ} \mathrm{C}$, as compared to $1^{\circ} \mathrm{C}$. The starting point for the onset of woolliness is 2 weeks. At that point nearly $50 \%$ of the fruits show woolly characteristics for $5^{\circ} \mathrm{C}$ storage confirming that this disorder does not appear at the same time for all the fruits. As hypothesized. by the end of the 4 weeks storage period. a substantially higher woolliness susceptibility is appreciated for the early ripeners (ER) fruits (between 70 and $80 \%$ of the total sample) when compared to the late ripeners (LR) fruits (from 10 to $30 \%$ of the total). The percentage of woolly fruits at a storage temperature of $1^{\circ} \mathrm{C}$, for all the ripeness stages at harvest, always remained below a $10 \%$.

Recommended storage temperatures for peaches are always below $5^{\circ} \mathrm{C}$. It appears that in actual post-harvest processing and marketing this temperature is very often reached in storage rooms, transportation trailers and market facilities and shelves.

\section{Conclusions}

(1) The onset of woolliness can be quantified by instrumental means, and described as lack of crispness. low hardness and low juiciness.

(2) Multi-modal distributions can be used to classily individual fruits into a number of clusters equal to the number of modes. In this study, the bimodal patterns of the compression crispness and shear crispness variables have been used to classify fruits as 'crispy' and 'non-crispy'.

Table 2

Main characteristics of the fruits labelled as crispy and non-crispy generated through a non-supervised clustering procedures (number of fruit tested $=270$ ) applied to the unimodal (1) and bimodal (2) variables; SD, standard deviation

\begin{tabular}{|c|c|c|c|c|c|}
\hline \multirow[b]{2}{*}{ Characteristics } & \multirow{2}{*}{$\begin{array}{l}\text { Analysis of } \\
\text { Lariance } F \text { value }\end{array}$} & \multicolumn{2}{|c|}{ Crispy } & \multicolumn{2}{|c|}{ Non-crispy } \\
\hline & & Mean & $S D$ & Mean & $S D$ \\
\hline Reflectance at $680 \mathrm{~nm}$ (1) & $112 \cdot 73$ & 36.92 & $6 \cdot 33$ & $45 \cdot 42$ & $7 \cdot 16$ \\
\hline Sugars (1) & $14 \cdot 14$ & 1085 & 1.15 & $10 \cdot 22$ & 1.62 \\
\hline Acidity (1) & $125 \cdot 43$ & 156.57 & 20.50 & $122+10$ & $30 \cdot 05$ \\
\hline M-Taylor firmness (2) & $536 \cdot 75$ & $35 \cdot 17$ & $12 \cdot 18$ & 8.97 & 667 \\
\hline Compression hardness (2) & $281 \cdot 40$ & $22 \cdot 41$ & $8 \cdot 83$ & 793 & 5.76 \\
\hline Rupture crispness (2) & $965 \cdot 00$ & 83.80 & $25 \cdot 25$ & 13.84 & $11 \cdot 61$ \\
\hline Shear crispness (2) & $700 \cdot 49$ & $64 \cdot 53$ & $18 \cdot 71$ & $15+46$ & $12 \cdot 67$ \\
\hline Absorbed energy (1) & 185.06 & $21 \cdot 81$ & $13 \cdot 63$ & 11.69 & $7 \cdot 32$ \\
\hline Lack of elasticity (1) & $204 \cdot 91$ & $39 \cdot 06$ & 8.91 & $56 \cdot 28$ & $11 \cdot 19$ \\
\hline Restitution energy (1) & 288.69 & 11.95 & 5.67 & $3 \cdot 24$ & 2.79 \\
\hline Compression juiciness (1) & $21 \cdot 12$ & 379.53 & 11980 & $309+89$ & $135 \cdot 55$ \\
\hline
\end{tabular}




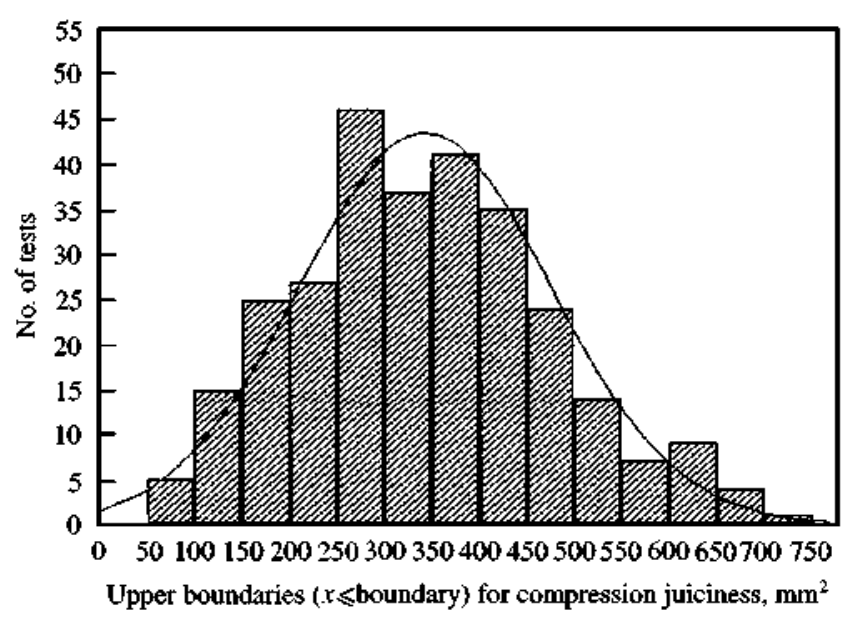

Fig. 4. Histogram observed for compression juiciness in $\mathrm{mm}^{2}$ of the juice spot created by compression of cylindrical test pieces (2 mm deformation): expected nomal

(3) The characterization of a bimodal distribution for the values of compression crispness and shear crispness is related to a very quick transition of the fruits from non-woolly to woolly, so that a sigmoidal behaviour is found.

(4) The instrumental juiciness has a pattern of a more gradual evolution than that of compression and shear crispness, the histogram does not show a quick transition (sigmoidal behaviour) and therefore no bimodal distribution is shown.
(5) In order to establish several degrees of juiciness within the fruits labelled as non-crispy, a partition according to compression juiciness in $\mathrm{mm}^{2}$ can be made. High, intermediate and low juiciness clusters within the non-crispy fruits have been established.

(6) The labelling of individual fruits into several crispness/ juiciness categories allows the texture degradation process to be characterized and woolliness appears to be the last stage. It also allows some conclusions to be made from the experimental factors, e.g. woolliness starts to appear after a treatment of 2 weeks at a storage temperature of $5^{\circ} \mathrm{C}$. Fruits corresponding to the low ripeness stage and the medium ripeness stage are more susceptible to woolliness than the fruits at the highest ripeness stage at harvest.

(7) It could be expected, that individual fruits have their own pattern regarding the onset of woolliness, as not all the fruits corresponding to replications of the same experimental conditions develop woolliness at the same time. Since $50 \%$ of the fruits show woolly characteristics for $5^{\circ} \mathrm{C}$ storage. This confirms the need of a fruit-by-fruit identification procedure for woolly fruits.

(8) Further analysis has been programmed, with the objectives of validating the established models, and of assessing the classification accuracy of the identification procedure (\% of incorrectly classified woolly fruits, when compared to a trained sensory panel). Also, on the basis of these results, the development of non-destructive instrumental methods to assess woolliness has been programmed.

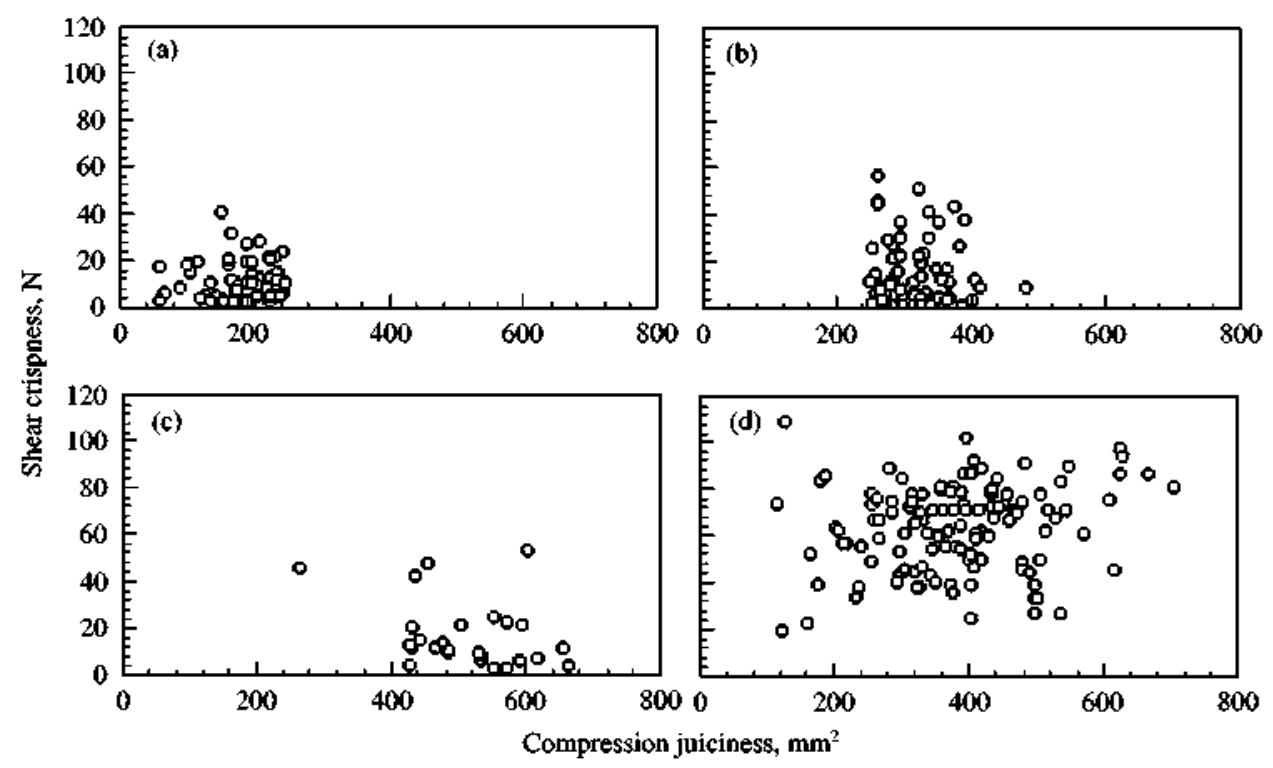

Fig. 5. Compression juiciness in $\mathrm{mm}^{2}$ and shea crispness in $N$ characteristics of the fou categories: (a) woolly (non-crispy, low juiciness): (b) non-crispy, mediun juiciness; (c) non-crispy, high juiciness; and (d) crispy 
Table 3

Study of the experimental factors in relation to the woolly fruits assessed within the new developed data analysis procedure for 0-4 weeks of storage, three ripeness stages at harvest and two storage temperatures

\begin{tabular}{|c|c|c|c|c|c|c|c|c|c|}
\hline \multirow[b]{4}{*}{$\begin{array}{l}\text { Storage period, } \\
\text { week }\end{array}$} & \multirow[b]{4}{*}{$\begin{array}{c}\text { Ripeness stage } \\
\text { at hartest }\end{array}$} & \multicolumn{8}{|c|}{ Number of fruits } \\
\hline & & \multicolumn{4}{|c|}{ Storage temperature of $I^{\dot{C} \mathrm{C}}$} & \multicolumn{4}{|c|}{ Storage temperature of $5^{\circ} \mathrm{C}$} \\
\hline & & \multirow[b]{2}{*}{$\begin{array}{c}\text { Crispy } \\
(S F>40 N)\end{array}$} & \multicolumn{3}{|c|}{$\begin{array}{c}\text { Non-crispy } \\
(\text { Shear crispness }(S F)<40 \mathrm{~N})\end{array}$} & \multirow[b]{2}{*}{$\begin{array}{c}\text { Crispy } \\
(S F>4 O N)\end{array}$} & \multicolumn{3}{|c|}{$\begin{array}{c}\text { Non-crispy } \\
(\text { Shear crispness }(S F)<40 N)\end{array}$} \\
\hline & & & $\begin{array}{c}\text { High } \\
\text { juiciness } \\
\left\{a v=510 \mathrm{~mm}^{2}\right\}\end{array}$ & $\begin{array}{c}\text { Intennediate } \\
\text { juiciness } \\
\left\{a v=321 \mathrm{~mm}^{2}\right\rangle\end{array}$ & $\begin{array}{c}\text { Woolly } \\
(\text { low juiciness }) \\
\left(a v=176 \mathrm{~mm}^{2}\right)\end{array}$ & & $\begin{array}{c}\text { High } \\
\text { juiciness } \\
\left\{a v=510 \mathrm{~mm}^{2}\right\rangle\end{array}$ & $\begin{array}{c}\text { Intennediate } \\
\text { juiciness } \\
\left\langle a v=321 \mathrm{~mm}^{2}\right\rangle\end{array}$ & $\begin{array}{c}\text { Woolly } \\
\text { (low juiciness }) \\
\left(a v=176 \mathrm{~mm}^{2}\right)\end{array}$ \\
\hline \multirow[t]{3}{*}{0 weeks } & First & 10 & 0 & 0 & 0 & 10 & 0 & 0 & 0 \\
\hline & Second & 6 & 1 & 3 & 0 & 6 & 1 & 3 & 0 \\
\hline & Third & 2 & 4 & 2 & 1 & 2 & 4 & 2 & $1^{*}$ \\
\hline \multirow[t]{3}{*}{1 week } & First & 10 & 0 & 0 & 0 & 8 & 0 & 1 & 1 \\
\hline & Second & 10 & 0 & 0 & 0 & 4 & 1 & 5 & 0 \\
\hline & Third & 2 & 5 & 2 & 1 & 0 & 4 & 6 & 0 \\
\hline \multirow[t]{3}{*}{2 weeks } & First & 10 & 0 & 0 & 0 & 5 & 0 & 1 & 4 \\
\hline & Second & 9 & 0 & 1 & 0 & 0 & 0 & 6 & 4 \\
\hline & Third & 6 & 1 & 3 & 0 & 0 & 2 & 3 & 5 \\
\hline \multirow[t]{3}{*}{3 weeks } & First & 10 & 0 & 0 & 0 & 0 & 0 & 2 & 8 \\
\hline & Second & 7 & 1 & 1 & 1 & 0 & 0 & 3 & 7 \\
\hline & Third & 5 & 5 & 0 & 0 & 0 & 1 & 8 & 1 \\
\hline \multirow[t]{3}{*}{4 weeks } & First & 10 & 0 & 0 & 0 & 0 & 0 & 3 & 7 \\
\hline & Second & 6 & 0 & 4 & 0 & 0 & 0 & 2 & 8 \\
\hline & Third & 6 & 1 & 3 & 0 & 3 & 0 & 4 & 3 \\
\hline
\end{tabular}

$S F$, shear crispness maximum force. * One set of peach data was lost. 
(9) The fruit-by-fruit analysis of physical (textural) instrumental parameters leads to coherent and useful conclusions for the assessment of the disorder called 'woolliness' in individual fruits. It leads to encouraging results that may also be effective for studying similar problems of texture degradation in other species like apples or tomatoes, as well as for studying other internal disorders or quality attributes.

\section{Acknowledgements}

Supported by EC Project FAIR CT960302: "Mealiness in fruits, consumer perception and means for detection' and ALI 94-1082 Project: 'Sensing colour stability and mixtures of powder paprika using optical reflectance and image analysis'.

\section{References}

Barreiro P; Ortiz C; Ruiz-Altisent M; De Smedt V; Schotte S; Andani Z; Wakeling I; Beyts P K (1998a). Comparison between sensorial and instrumental measurents for mealiness assesment in apples. A collaborative test. Journal of Texture Studies. 29(5), 509-525
Barreiro P; Ortiz C; Ruiz-Altisent M; Recasens I; Asensio M A (1998b). Mealiness in apples: comparison between human and instrumental procedures and results. SENSORAL 98 (International Workshop on Sensing Quality of Agricultural Products, Montpellier 24-27 February). Montpellier: Veronique Bellon-Maurel (CEMAGREF Editions). Vol. 1, pp 245-257

Bruhn C M (1995). Consumer and retailer satisfaction with the quality and size of California peach. Journal of Food Quality. 18(3), 241-256

Harker F R; Hallett I C (1992). Physiological changes associated with development of mealiness of apple during storage. HortScience, 27, 1291-1294

Izquierdo L; Costell E (1997). Mealiness in fruits, consumer perception and means for detection; 18 Months Report. Institute of Agrochemistry and Food Technology. EC. Project FAIR CT960302

Izquierdo L; Costell E (1998). Mealiness in fruits, consumer perception and means for detection; 2nd Year Report. Institute of Agrochemistry and Food Technology. EC Project FAIR CT960302

Kailasapathy K; Melton L D (1992). Woolliness in stone frujts. ASEAN Food Journal, 7(1), 13-16

Lopez J L; Valero M M; Ruiz-Altisent M (1996). Harinosidad en manzana: un sondeo a los detallistas de fruta de Madrid [Mealiness in apples: a survey on Madrid fruit retailers]. Fruticultura Profesional. 77, 48-55

Paoletti F; Moneta E; Sinesio F (1993). Mechanical properties and sensory evaluation of selected apple cultivars. Lebensm.-Wis. ul. - Technology. 26, 264-270 